\title{
Design of Intelligent Monitoring and Controlling System for Deer Based on Internet of Things
}

\author{
Shi-Jun LI ${ }^{a}$, Ji LI, He GONG, Jian LI, Hong-Jun GU ${ }^{\text {b }}$ \\ Jilin Agricultural University, Changchun 130118, Jilin, China \\ alsj0883@sina.com, bohj_dennis@163.com
}

Keywords: IOT, standardized breeding, deer, ZigBee.

\begin{abstract}
There exist issues of fast environmental degradation, poor intelligence, and low management efficiency with the expansion of breeding deer scale. This paper presents the intelligent monitoring and controlling system for deer based on internet of things (IOT). This system includes multiple wireless sensor network nodes, ZigBee routing nodes, ZigBee Ethernet gateway, server, client and video monitoring devices. Wireless sensor network nodes connects ZigBee Ethernet gateway via ZigBee routing nodes. ZigBee Ethernet gateway access client server to transmit data. Video monitoring device includes video cameras, exchangers, hard disk video recorders and display device. The cameras send the environment information to hard disk video recorder via the exchangers, and the environment parameters can be shown in the screen. Wireless sensor network includes electronic rings, RF read-write monitoring nodes, water and eating monitoring nodes, spray monitoring and controlling nodes, and sunlight monitoring nodes. This system can meet the needs of the deer growth environment, save resources and labor, reduce disease incidence, improve the quality of deer antler and rate of survival, which has important guiding significance to large scale production of deer in the future.
\end{abstract}

\section{Introduction}

In recent years, the deer production has been paid widely attention. In China, there exist about 600 thousand deer ranking first in the world. Sika deer is the main pharmaceutical economic animals and deer antler have special curative effect, which have been approved by international organizations and experts. As the hometown of Chinese sika deer, Jilin province has the obvious advantages in breeding deer.

At present, the deer farms still adopt the traditional breeding method. Unstable product quality, low yield, poor efficiency, severe resource depletion problems exist for a long time due to human factors. A mature system with automatic monitoring and controlling deer breeding environment does not appear. Although the RFID technology based on IOT has been used in the automatic monitoring of pig and cow breeding, the life habit of the deer is different, and deer farms need to simulate the wild environment. So the intelligent monitoring and controlling of deer breeding need to be designed individually.

There are rare literatures in China. In $2015 \mathrm{Wu}$ Juxin in Jilin agricultural university wrote a master thesis paper about deer product quality monitoring system based on IOT, which realizes automatic control system in the deer growth environment and precise feeding, and a digital information integrated service management platform was designed [1]. In 2016 Lin Yun uses ZigBee technology to build the sheep farm intelligent sunlight system, and this system can improve the sheep farm environment [2]. In 2015 ZHANG Yan uses IOT technology to build a safety tracebility platform for the whole industry chain of Laiwu pig, in which all data of the whole industry chain including Laiwu pig breeding, cultivation, slaughter, processing, logistics and sales are collected using IOT sensor nodes [3]. In 2013 BAI Hongwu constructs boar management platform based on IOT technology, in which an integrated solution for automatical management, epidemic prevention and food safety of farms is proposed [4]. Zhang Xiaoping studies the intelligent cowshed management system consisting of upper management platform software, transmission equipment, terminal controller and execute components, forming an efficient management mode, which is easy to use and can be 
accessed by remote control [5]. In future, the domestic deer breeding develops toward large-scale and scientific management direction. IOT technology has been used in more agricultural fields [6].

\section{Overall System Framework}

The overall system framework is shown in Fig .1, system nodes collect environmental parameters, including video information, and conveys them to the integrated service management platform (ISMP) via wireless sensor network, mobile network or internet. ISMP saves the environmental parameters and sends the data and information to the mobiles and computers of administrators. The administrator can give the corresponding commands to the control and feeding equipment. ISMP can control the related devices automatically under the absence of the administrator management.The system can be divided into three sections: automatic feeding and watering and spray control, growth environmental monitoring and control, and integrated information service management platform.

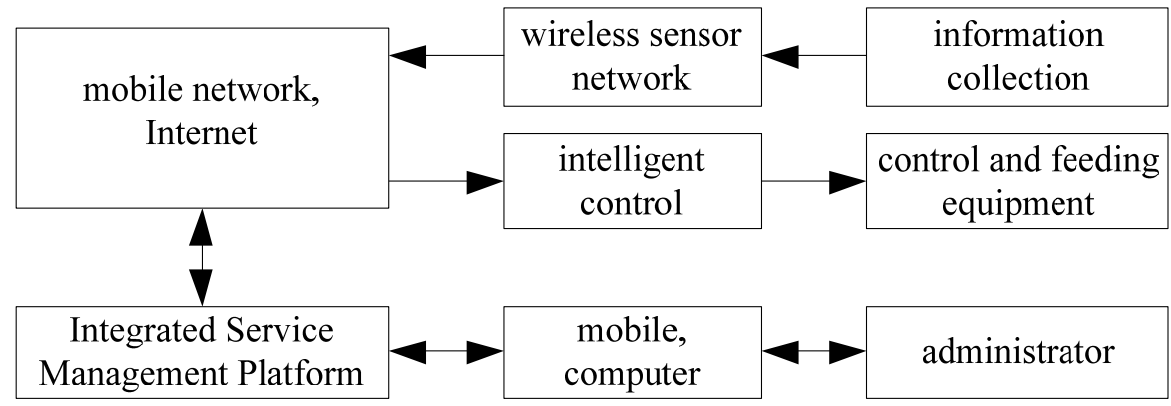

Fig. 1 The overall system framework

\section{System Working Process}

The system working process is shown in Fig .1. The sensor nodes can collect the environmental parameters of temperature, humidity, illumination, $\mathrm{CO}_{2}$ concentration, which can be sent to ISMP via the wireless sensor network, mobile and Internet. ISMP analyzes the data and gives the control instructions to run the automatic control equipment.

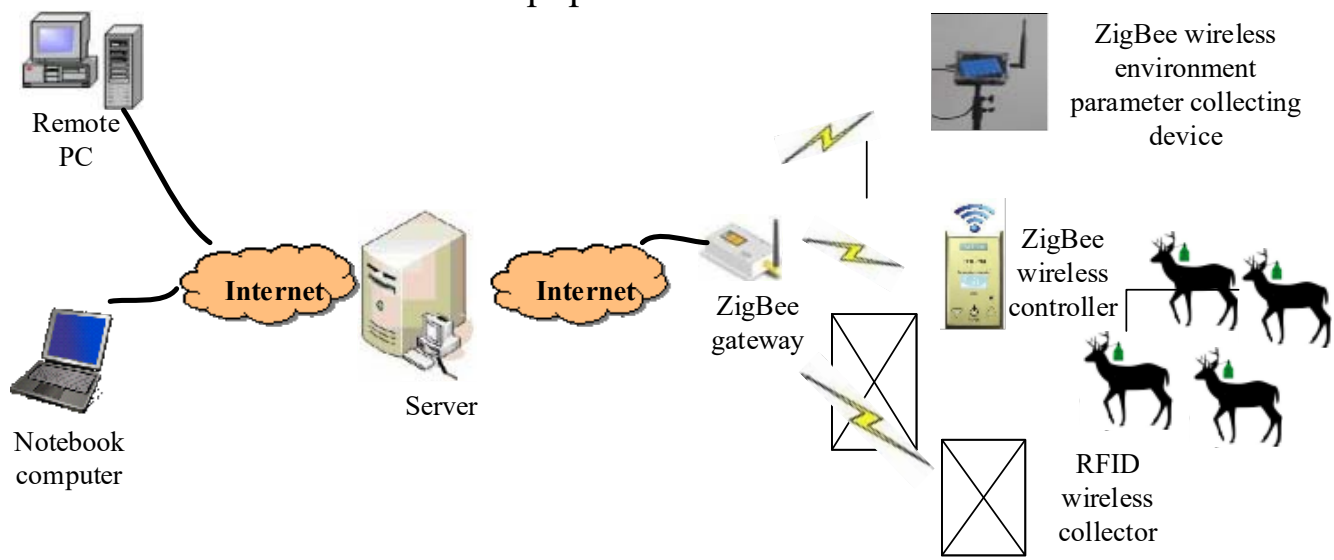

Fig. 2 System working process

ISMP sends the related parameters to the administrators and feeders via PC or cell phone, which make them mater the deer growth information at any time. The feeders can also give some instructions, such as feeding and cleaning, to ISMP via PC or cell phone for performing intelligent control.

\section{Automatic Precise Feeding, Watering and Spray Control}

Regular feeding, watering and spray may be realized by timers. The administrators can modify the time. The detailed controlling node sketch is shown in Fig .3. Quantitative food, regular watering and spray ensure that the deer grow at the same speed, gastrointestinal disease incidence decreases sharply, survival rate increases to some extent, and quality of deer antler can be improved. 


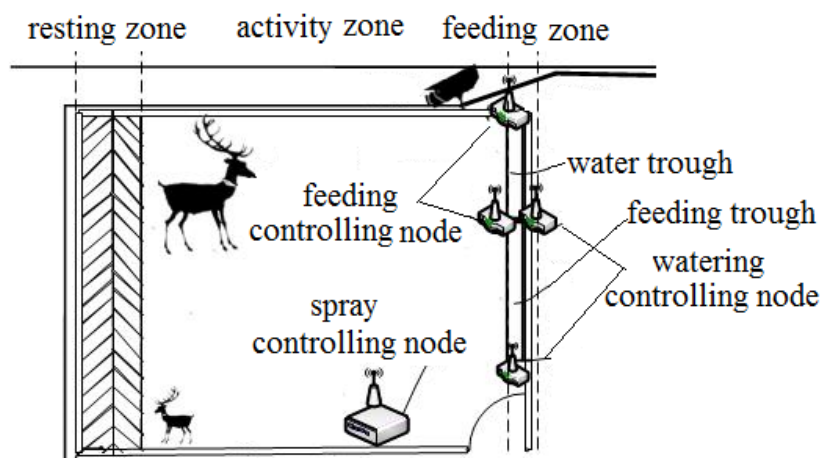

Fig. 3 Automatic feeding, watering and spray sketch

\section{Data Collecting and Controlling Node Design}

The CC2530 is chosen as the core of collecting and controlling node. It is a true system-on-chip solution for IEEE 802.15.4, ZigBee and RF4CE applications. The CC2530 combines the excellent performance of a leading RF transceiver with an industry-standard enhanced $8051 \mathrm{MCU}$, in-system programmable flash memory, 8-KB RAM, and many other powerful features. This system adopts CC2530F256 with $256 \mathrm{~KB}$ of flash memory. The detailed minimum system diagram is shown in Fig .4. And Fig .5 gives the node diagram with two $1.5 \mathrm{~V}$ battery power supply, in which many sensors are integrated. These nodes can collect environmental parameters of air temperature and humidity, $\mathrm{CO}_{2}$ concentration, illumination and ammonia concentration. According to the requirements of deer growth, the system controls ventilation, lighting and heating, automatically to adjust the environment parameters.

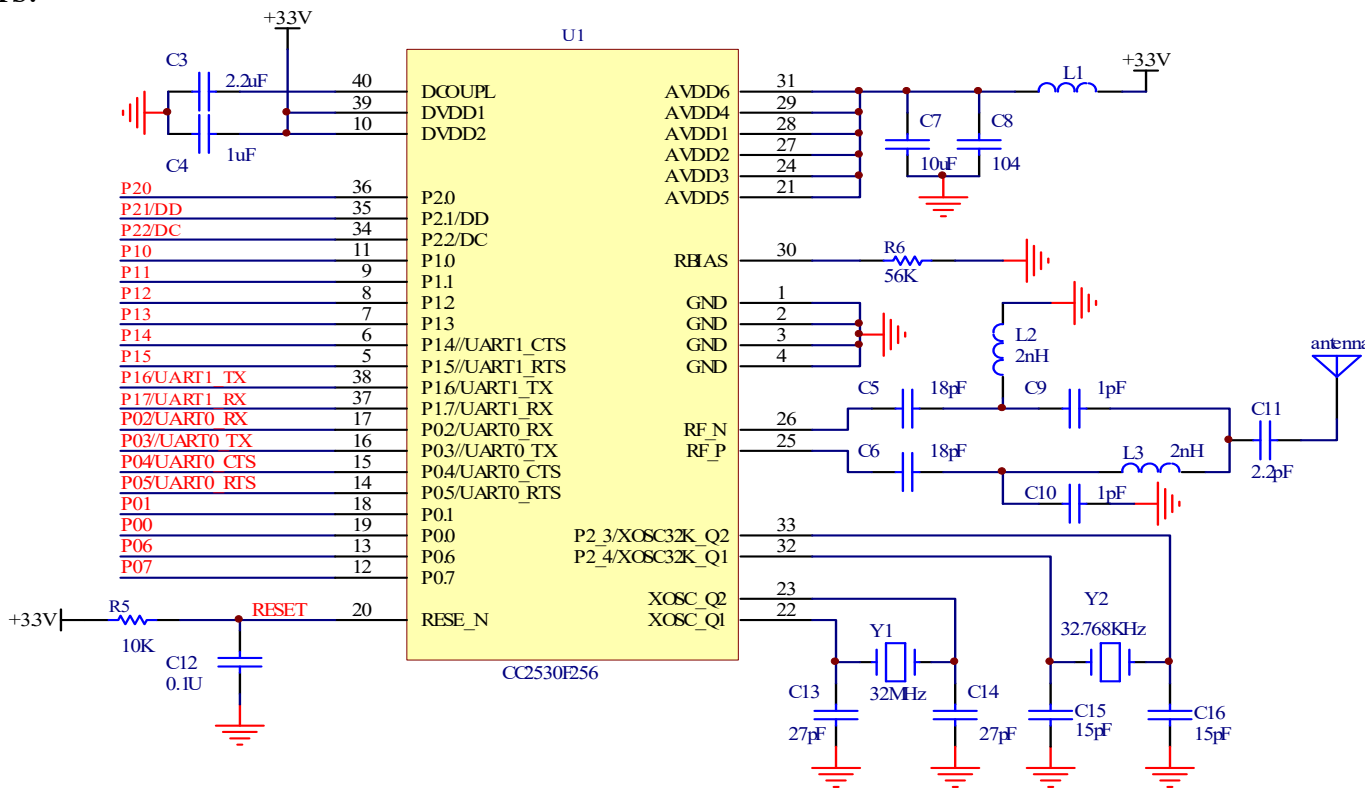

Fig. 4 CC2530 schematic diagram

Fig .6 shows the video transmission sketch. Cameras can get the video information from the deer pen, which can be sent to ISMP, the user can view the conditions of the deer by displaying device at any time. So the system ensures deer grow in the optimal environment, reduce the disease incidence.

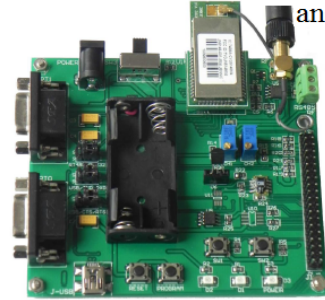

Fig. 5 Node diagram

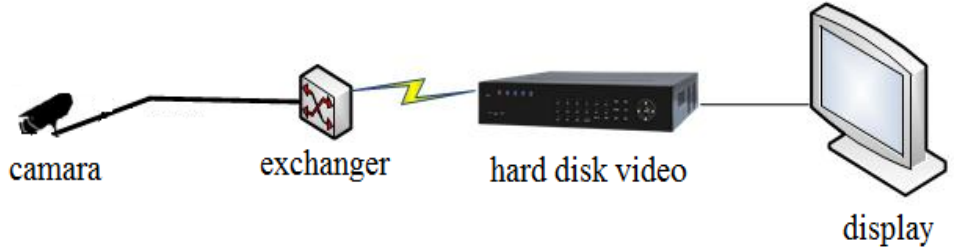

Fig.6 Video transmission sketch 


\section{Integrated Service Management Platform}

ISMP is also an expert decision support system, using ASP.Net development framework and B/S architecture design. All the deer information is stored in the system. According to the deer conditions at every stage, this system can make a comprehensive analysis and judgment, and give the related instructions to administrate the epidemic prevention, breeding, feeding. When the deer farm lies in the abnormal conditions, ISMP launches the alarm devices and sends the alarm message to the administrators.

\section{Conclusions}

This paper designs an intelligent monitoring and controlling system for deer based on IOT. This system includes three parts: automatic precise feeding, growth environment monitoring and control, and integrated service management platform. The first task is to design an automatic precise feeding system which saves a lot of labor and decrease deer food spoiled. And the second one is design growth environment monitoring and control system which ensures the good sanitary conditions deer need. The third one is to design ISMP which can store, analyze and convey much related data, and give the suitable control instructions. This project solves the issues of inefficiency, fast environmental degradation, and easy disease spread in the deer breeding process. This system can improve the production efficiency and economic benefit for the prospective scale deer breeding.

\section{Acknowledgments}

The authors wish to express their gratitude to the projects: Deer Breeding Intelligent Monitoring and Controlling System Based on RFID of IOT, Design of Standardized Breeding System for Rabbits Based on IOT from Education Department of Jilin Province, Jilin Province Economic Structural Adjustment Leading Fund Special Project (No. 2014Y108) and Changchun City Science and Technology Plan Project (No. 14nk029, No. 13KG71), Key Tackling Item of Jilin Province Science \& Technology Department (No. 20140204045NY), Jilin Province Science \& Technology Department Project (No. 20150204058NY, No. 20140204045NY) for their generous support of this work.

\section{References}

[1] WU Ju-Xin. Deer Products Quality Monitoring System Based on Internet of Things [D]. Changchun: Jilin Agricultural University, 2015, in Chinese.

[2] PAN Yun. Research on the Sheep Farm Intelligent Sunlight System. [J]. Information and communications, 2016, (2): 115-116, in Chinese.

[3] ZHANG Yan, LIU Ping-Zeng, YU Qun, et al. Safety Traceability Platform Building for the Whole Industry Chain of Laiwu Pig Based on IOT [J]. Journal of Chinese Agricultural Mechanization, 2015, 36(2):141 - 144, in Chinese.

[4] BAI Hong-Wu, FENG Guo-Xing, DING Wei-Rong, et al. Boar Management Platform Based on IOT Technology [J]. Intelligent Processing and Application, 2013, (3): 61-64, in Chinese.

[5] ZHANG Xiao-Ping, QIAN Guan-Hua, LI Chang-Chun, et al. Research on Intelligent Cowshed Management System [J]. Heilongjiang Science, 2015, (4): 42-43, in Chinese.

[6] GU Hong-Jun, ZHU Shi-Dong, and YANG Yan-Fen, et al. Design of Intelligent System for Watering Flowers Based on IOT [C]. Advances in Engineering Research, 2015: 1469-1473, in English. 